This study won the ML Roberts prize awarded for the best 4th year undergraduate research project at the Department of Physiotherapy, Auckland University of Technology in 2015. NZJP publishes the resulting paper without external peer review.

\title{
Gaining perspectives of people with stroke, to inform development of a group exercise programme: A qualitative study.
}

Candice Kitt* BHSC (Physiotherapy)

Department of Physiotherapy, Auckland University of Technology, New Zealand

Vanessa Wang* BHSC (Physiotherapy)

Physiotherapist, Auckland City Hospital, Auckland DHB, Auckland, New Zealand

Linda Harvey-Fitzgerald $P G$ cert (Rehabilitation)

Team Leader - Allied Health, Auckland City Hospital, Auckland DHB, Auckland, New Zealand

Nicola Kayes $P h D$

Director of Centre for Person Centred Research, Auckland University of Technology, New Zealand

Nicola Saywell MHSC

Lecturer, Auckland University of Technology, New Zealand

*At the time of this study, were undergraduate students at the Department of Physiotherapy, Auckland University of Technology.

\section{ABSTRACT}

This study explored the perspectives on participation in group rehabilitation in the inpatient setting for people with moderate to severe stroke. A qualitative descriptive study using in-depth semi-structured interviews ascertained the experiences and impressions of participating in a group exercise programme. Six participants were interviewed, and analysis of the data identified four main themes: Loss of self; I can't do it alone; Being part of the whole and Therapeutic approach in the context of personhood. These themes allowed identification of key components that may inform development of group exercise for people with moderate to severe stroke. People with moderate to severe stroke expressed feelings of loss of who they had been. Some were reluctant to join group exercise; the need to be part of a group was sometimes overwhelmed by doubt that they could participate in a meaningful way. Those who overcame their reluctance to join found a benefit in shared experience and mutual assistance to progress. The way they were treated and the degree their autonomy was respected by physiotherapists had a significant impact on their willingness to exercise and their enjoyment of group sessions. These findings will assist the development of a group programme to increase opportunities for activity in the inpatient stroke rehabilitation setting.

Kitt C, Wang V, Harvey-Fitzgerald L, Kayes N, Saywell N (2016) Gaining perspectives of people with stroke, to inform development of a group exercise programme: A qualitative study. New Zealand Journal of Physiotherapy 44(1): 58-64. doi: 10.15619/NZJPI44.1.07

Keywords: Stroke, Group exercise, Qualitative, Severity, Participation

\section{INTRODUCTION}

Stroke is the third leading cause of death and the greatest cause of disability in adults in New Zealand. Approximately 9,000 strokes are reported every year and there are an estimated 60,000 stroke survivors at present (Ministry of Health 2014). Approximately $43 \%$ of survivors experience a moderate to severe disability and many continue to require assistance with at least one activity of daily living after discharge (Hartman-Maeir et al 2007). Despite the significant number of people with a moderate to severe stroke, research has consistently shown that this population does not receive the recommended amount of therapy, as the ratio of physiotherapists to patients in an acute stroke unit is often insufficient (Bernhardt et al 2004).
Recent research has shown that an increase in the amount of activity undertaken by people with severe stroke is possible and well tolerated (Askim et al 2012). One potentially effective way to increase activity in the inpatient rehabilitation setting is to include patients in group activity. Several studies have demonstrated that group-based programmes lead to positive outcomes for people with stroke, including psychosocial gain, positive impact on confidence, and functional improvement (Graham et al 2008, Schouten et al 2011, Song et al 2015). Depression is also commonly seen in people after stroke and several studies have indicated that group-based classes may increase confidence and hope with a consequent reduction in depression (Anderson and Whitfield 2013, Townend et al 2010). However, people with moderate to severe stroke are frequently 
excluded from studies investigating group-based rehabilitation due to their limited ability to participate without assistance, so little is known about its potential use in this population. The current study aimed to explore the experiences and perceptions of group exercise programmes from the perspectives of people with moderate to severe stroke in the inpatient setting. The findings will inform the development of a group-based rehabilitation programme in the acute stroke rehabilitation setting.

\section{METHOD}

\section{Design}

This study drew on Qualitative Descriptive Methodology, using semi-structured individual interviews. This methodology has been identified as being useful to inform intervention development (Sandelowski 2000, Sullivan-Bolyai et al 2005). Ethics approval was obtained from AUT Ethics Committee (14/154) and institutional approval was gained from Auckland District Health Board Ethics Committee prior to commencing this study.

\section{Participants}

People were eligible to take part if they: (1) had sustained a moderate to severe stroke, (a score of 5 or above on the National Institutes of Health Stroke Scale); (2) were 65 years old or over; and (3) were able to converse in English. Exclusion criteria were: (1) communication impairment (sustained expressive / receptive dysphasia) that would impact their ability to engage in the interview process; and (2) a score below 4 out of 6 on the 6-item cognitive impairment test (Slater and Young 2013), conducted by an experienced senior clinician.

Participants were identified and recruited from an Older Persons Health ward in an inner city hospital between April and June 2015. Convenience sampling was used to identify potential participants due to the unpredictability of the occurrence of the condition, and the time and resource constraints on student researchers. Effort was however made to include a diversity of people with regard to sex and ethnic diversity to capture a breadth of perspectives and improve transferability of findings when applied to similar settings and contexts. Informed consent was sought from all potential participants who met the inclusion criteria and agreed to participate in the study.

\section{Data Collection}

The interviews were conducted face to face by a student researcher (CK or VW) and a senior clinician (LH-F). Each interview was undertaken prior to patient discharge from $\mathrm{OPH}$, and took place in a private room on the ward. Family/whānau were invited to attend at the discretion of the participant. The interview questions (Appendix 1) were designed to explore the participant's rehabilitation experience and perspective during their hospital stay, and to help inform structure and content of future group-based programmes. The interviews were audiotaped and transcribed verbatim. Audio recordings and transcripts were kept in password secured files and pseudonyms were assigned to protect patient anonymity. Interviews were a maximum of one hour to avoid fatigue and terminated early if the participant so requested or if the information already gained satisfied the purpose of data collection.

\section{Data Analysis}

This study followed conventional content analysis, an inductive approach guided by step-by-step procedures to avoid preconceived concepts, suggested to be appropriate when there is limited research literature available on the topic (Hsieh and Shannon 2005). The initial analysis was carried out by the two student researchers. The transcripts were read repeatedly in order to become familiar with the data, then phrases and sentences were initially coded manually after each interview. Key thoughts and concepts were highlighted independently and discussed between student researchers. New data and codes were checked against the preliminary concepts. The codes were evaluated and grouped into categories based on their similarity. All transcripts were then uploaded to NVivo, a qualitative data management software (QSR International Pty Ltd. Version 10). Iterative comparison of coded data within categories was undertaken to identify themes. Two random transcripts were sent to senior qualitative researchers (NK and NS) for analysis, then the study team met as a group and discussed the analysis and interpretation to ensure consistency in interpretation of data. Following this, a tabular form of key categories, annotation and illustrative quotes was drafted by student researchers and sent to the two senior researchers to assist theme development. The senior researchers assisted in clarifying themes and the final themes were agreed upon after discussion.

\section{RESULTS}

\section{Participant Characteristics}

Six participants were recruited to take part in the study: four males and two females with a median age of 81 years (range 76-93). Five of the six participants identified as European New Zealanders and one as Indian. All participants had been independent in activities of daily living prior to the stroke and none regained independence prior to discharge from hospital. Table 1 provides a summary of participant characteristics and their pseudonyms.

\section{Interview findings}

Four main themes were drawn from the data. The themes were, Loss of self, I can't do it alone, Being part of the whole and Therapeutic approach in the context of personhood. The themes are described in more detail below.

\section{Theme 1: Loss of self}

This theme represents participants' views and feelings poststroke and encompasses the effects it has on their lives. It embodies feelings of helplessness, loss of hope and identity and an end of a former life. The participants often appeared to experience the loss of self through a loss of roles or meaningful activities. One participant expressed her loss of role as a mother and portrayed feelings of guilt when she stated:

I feel like they could've done without having a mother falling by the wayside. I couldn't have had a stroke at a worse time. (Sally, 84 yrs)

A majority of the participants' stories portrayed feelings of sadness, with their former lives barely seeming real. Being unable to participate in the same way as prior to their stroke led to a loss of hope of recovering their former self. John expressed 
Table 1 : Participants characteristics

\begin{tabular}{|c|c|c|c|c|c|}
\hline Pseudonym & Age $(Y)$ & Sex & Ethnicity & $\begin{array}{l}\text { Length of } \\
\text { Stay (days) }\end{array}$ & Social situation \\
\hline Sally & 84 & $\mathrm{~F}$ & $\begin{array}{l}\text { New Zealand } \\
\text { European }\end{array}$ & 43 & $\begin{array}{l}\text { Previously lived alone in independent unit. } \\
\text { Discharged to private hospital. }\end{array}$ \\
\hline John & 86 & M & $\begin{array}{l}\text { New Zealand } \\
\text { European }\end{array}$ & 35 & $\begin{array}{l}\text { Previously lived independently in own home. } \\
\text { Discharged to private hospital. }\end{array}$ \\
\hline Mike & 78 & M & $\begin{array}{l}\text { New Zealand } \\
\text { European }\end{array}$ & 45 & $\begin{array}{l}\text { Previously lived with wife in own home. Discharged } \\
\text { home with increased package of care. }\end{array}$ \\
\hline Maggie & 93 & $\mathrm{~F}$ & $\begin{array}{l}\text { New Zealand } \\
\text { European }\end{array}$ & 20 & $\begin{array}{l}\text { Previously lived independently in retirement village. } \\
\text { Assessed as requiring private hospital care. }\end{array}$ \\
\hline David & 79 & M & $\begin{array}{l}\text { New Zealand } \\
\text { European }\end{array}$ & 20 & $\begin{array}{l}\text { Previously lived with partner in pension flat. } \\
\text { Discharged home with increased package of care. }\end{array}$ \\
\hline Ravi & 76 & $\mathrm{M}$ & Indian & 34 & $\begin{array}{l}\text { Previously lived with wife at home; discharged home } \\
\text { with increased level of home care. }\end{array}$ \\
\hline
\end{tabular}

Notes: $Y$, years; $M$, male; $F$, female

this sense of loss and the impact it had on his hope of recovery:

Well, I would wish to be the fitness sort of person I used to be because I, we'd do long walks you know and they are only dreams now to me... all of them. It was disgusting to me... what I was doing [compared] to what I used to be able to do. (John, 86 yrs)

The emotional response to the sense of loss may impact engagement. Frustration or even despair was sometimes articulated:

All those good things in my life are over and that is hard to come to grips with. (John, 86 yrs)

Well of course you feel very frustrated when you can't do what you used to be able to do without even thinking about it. (David, 79 yrs)

Physical activity which did not seem to have any link to real life was negatively perceived. Each participant interviewed indicated the value in purposeful activities which had a link to their former life. However, they reported that it was not always clearly explained why they had to go to the gym and do exercises when they had never been physically active pre- stroke. John explained:

I never was the exercise type; I did sports to stay active like golf. (John 86yrs)

Other participants went into great detail of activities they enjoyed such as knitting, social clubs and cooking, but were unable to link their rehabilitation exercises to a return to those activities. When asked if they would have participated in group exercises to improve their fitness and strength to get back to those actives there was unanimous agreement that they would.

Some participants reflected on the potential for a group programme to reveal activities they were no longer able to do and the potential for this to hinder engagement and impact negatively on mood. However, sharing the experience of loss of self with other group participants appeared to be helpful in envisaging hope of a different self. When reflecting on observing others with similar limitations, Maggie reported:

You can see the others have improved, well maybe you can improve as well as that's you. And it's not the end of the world but you have to adjust to things being different. (Maggie, 93 yrs)

People who were unable to envisage a different normal had a very different outlook on the situation. Another participant attending the same exercise group stated: "It's all gone..." (John, 86 yrs).

\section{Theme 2: I can't do it alone}

This theme represents the initial apprehension about engaging in a group programme. Support and encouragement from others was reported by several participants to have helped them through that early vulnerability.

Everyone sort of looked at each other and then they'd smile... you're all a bit nervous then you get a bit more confident as the days go on, and it's quite fun once you get over being frightened....or not frightened, but cautious. (Maggie, 93 yrs)

Maggie's statement seemed to suggest a sense of hope and belonging. Observing and learning from others in a similar situation seemed to uplift spirits and instill confidence. Having the opportunity to relate to others may have offered the support needed to gain courage and trust in one's new self and the motivation to engage in the group programme. When engagement with others was not possible the experience appeared to be very different. Mike was an inpatient in the same ward as Maggie, but was in isolation due to a virus. He 
stated: "I'm so depressed...I've had enough." (Mike, 78 yrs)

Being in a group setting rather than alone and being able to gauge improvements relative to others can create a sense of responsibility for progress:

Is there anything that I can do to help myself? is what it really boils down to. If I'm not making progress, it's me who's at fault. (Sally, 84 yrs)

However, it also appeared important for there to be a good level of support from staff to counter feelings of powerlessness. This suggests the need for a balance between intrinsic and extrinsic feedback, so progress is not hampered by feelings of guilt from unhelpful comparison with others. This is reflected in Sally's comments, as she went on to say:

You have no idea the way I envy the other women in the ward who have worked so hard, and who can actually get out of bed, and back in again without falling over. And they walk to the toilet, by themselves. They must work very, very hard. A lot harder than me obviously. (Sally, 84 yrs)

There were also occasions mentioned when attendance at group activities was limited by a belief (perceived or real) that you had to be at a certain level to engage in group exercises. For example, Ravi commented: "I'd love to go there, but I can't do it myself. Because I'm unable to walk properly, stand properly." (Ravi, 75 yrs)

Some participants expressed a keenness to attend a class but felt they lacked the ability to do it alone and a strong desire not to be a burden to others meant they did not ask for help and consequently missed out. David relates why he didn't ask for help: "They have lives as well... [Referring to staff]" (David, 79 yrs)

An opposing view was expressed by others who could not manage activities such as toileting, walking and group programmes. There was a feeling that the assistance required was not available due to insufficient staff-to-patient ratios to meet that need:

I just continue to walk, because if I only do half an hour walking I have to wait for the next day, the nurse took me for a walk around once, instead of once, they should take me two, three times. (Ravi, 75 yrs)

A surprising finding within this theme was that despite the expressed need for help, none of the participants wished to have their families attend the exercise programme to offer additional support. Some participants stated they did not want to "burden (their) loved ones". When asked if he would want his family to be part of an exercise group with him, John pointed out that they were already stretched with doing things for him.

They are putting in more time than you can dream now, I mean [name of daughter] is only here because she works at ...... school in the office, and has a tough job there. (John, 86 yrs)

Theme 3: Being part of the whole

This theme signifies the importance of human interaction, connection and support that can be offered by group activities. Creating relationships early in a hospital stay with peers or instructors may facilitate engagement and improve confidence. A regular group exercise participant shared her experience of when she first attended class: "We are all in the same boat." (Maggie, 93 yrs)

Maggie also acknowledged the shared experience and role that others who were further along than her had as mentors in the group: "Some are better off, further ahead than others, but it doesn't seem to matter, 'cause they're sympathetic, they've been through it." (Maggie, 93 yrs)

The environment was frequently mentioned as an important factor in a sense of belonging and engagement in a group programme. Some clear recurring drivers which promote engagement were mentioned by participants. All participants stated the importance of music during exercise class. Some preferred something with a beat, others preferred country or rock ' $n$ ' roll and some could not say what they liked, but simply stated: "Music makes it better." (David, 79 yrs)

This seemed partly to do with creating a fun atmosphere in the group environment, which helps foster companionship. By building relationships with fellow group attendees, participants reported building trust, allowing fear and anxiety around exercise performance to ease.

It doesn't seem like work, it makes it seem more like fun, because you got the companionship, and you then know that no one is gonna let you fall or anything bad is going to happen. It then becomes quite fun. (Maggie, $93 \mathrm{yrs}$ )

Theme 4: Therapeutic approach in the context of personhood.

The interaction between patient and practitioner clearly impacts patients' engagement in physical activity. Knowing how much to push someone during a treatment session involves skill from the practitioner. When participants were asked if they were receiving adequate therapeutic intervention, five out of the six responded 'yes.' They enjoyed a balance of stimulation (exercises) and rests. Maggie (93 yrs) was asked:

Interviewer: In a normal day in hospital were there enough activities? Was it ever too quiet?

Maggie: The normal day, no, because something was happening most of the time. There's enough time to rest and get over it to want to do something else. (Maggie 93 yrs)

However, the therapeutic part of treatment needed to be balanced with being treated as a person. There were times when participants noticed they felt their personhood was not being taken into account and the mechanics of the interaction had taken over. One participant described their experience of being moved and handled in this way:

Everyone is trying to turn you over by grabbing your leg. Every finger nail, every thumb leaves a bruise. (Sally, 84 yrs).

This was not a common situation and several participants gave the opposing view, that when they were appreciated as an individual by the physiotherapist it stimulated engagement and participation: 
Well he has a pleasant nature and not pushy and doesn't keep telling me I walked 30 metres last time. (John, 86 yrs)

To ah get going...you rely on the instructors to ah .... point you in the right direction. (Mike, 78 yrs)

These statements illustrate the importance of considering individual preferences and needs within a therapeutic relationship and the potential influence that has on patient participation in exercise.

\section{DISCUSSION}

The findings from the study demonstrate that when developing an exercise programme there is far more to consider than suitable types of exercises, sets and repetitions. Rather, learning what matters to participants to make the exercises purposeful and enjoyable may encourage engagement and regular attendance. Poltawski et al (2015) found promoting a programme on factors such as enjoyment of recreation, increased self-esteem and life satisfaction enhanced the appeal of exercise. Health professionals often use standardised assessments to tailor programmes to a patient's level of impairment and spend less time gaining a clear understanding of their patients' former self and the impact the stroke may have had on their sense of self and quality of life. Research suggests that patients with significant disability can still have good quality of life, which is often the outcome most important to people after stroke (Aprile et al 2006). Our findings would suggest that acknowledging the sense of loss people have experienced and actively tailoring programmes to make them meaningful to participants have the potential to facilitate their engagement, and may have greater potential for impacting outcomes that matter most to patients.

Research suggests that some people find it difficult to recognise abilities because they are focused on their losses (Remer-Osborn 1998). Significant depression requiring treatment is strongly correlated with non-acceptance of impairment and affects as many as 50\% of people with stroke (Townend et al 2010). A strategy to help patients distinguish between functional loss and 'loss of self' is to focus on new ways to perform activities. To be able to offer support and guidance to see rehabilitation as a time of transition when they are learning new strategies may facilitate acceptance (Ellis-Hill et al 2008). If physiotherapists do not give time to allow the patient to adapt, patients can experience lack of motivation, fear and isolation, which impact engagement in group-based programmes (Nicholson et al 2013).

Findings from this research are congruent with previous research that the patient-therapist relationship is extremely important and may positively impact outcomes (Hall et al 2010). Participants valued choice and a rationale for a particular exercise. In addition, the feeling of increased control appeared to increase participation and engagement. Mangset and colleagues (2008) described the importance of patients being acknowledged as individuals and their autonomy respected. They found that when confidence and trust were formed between patient and professional, this improved the patient experience of rehabilitation. Increased pressure from policies in the hospital environment, such as monitoring discharge dates and reducing length of stay, can pressure healthcare professionals to push participants towards goals too early in their rehabilitation or not allow enough rest between interventions.

Research supports the benefits of family involvement in patient recovery; however, it also shows that families witnessing loved ones struggle can lead to emotional distress, grief, fear, anger at the patient and unrealistic expectations of the staff (RemerOsborn 1998). The finding of participants needing help but not wanting to burden their family was explored in a study following a family assisted stroke rehabilitation programme (Galvin et al 2014). They found that families generally reported less stress when involved fully in the rehabilitation, despite having to do more work. Physiotherapists may need to explore further a participant's desire to save their family work, to ensure that those who would gain some reassurance from being involved are not unwittingly turned away.

A social group, where participants are treated as 'us' rather than the individual, provides attendees with a sense of belonging and purpose (Anderson and Whitfield 2013). Five of the six participants in this study preferred to exercise in a group setting rather than one-on-one with their therapist. They felt their limitations were not put under the microscope and dissected; instead individuals were welcomed, introduced to others and able to work through the class with positive encouragement from peers and instructors. Desrosiers et al (2008) found that a greater acceptance of the consequences of stroke is facilitated by a higher level of social participation.

In terms of specific feedback regarding programme components our findings highlight the following key points: First, music was considered to be a fundamental requirement for any group exercise class by all the participants. A study by Jun et al (2013) found that music has the capacity to capture attention, generate emotion, change or regulate mood, increase work output, reduce inhibition and encourage rhythmic movement. Second, all participants agreed that undertaking meaningful exercises to help them regain activities of daily living was of great importance and promoted participation and engagement. However, the data did not identify specific types of exercises or method of delivery. Some enjoyed a routine and stated they liked to know what was coming, others favoured variety in a circuit style workout. Third, social interaction was highlighted throughout our data and the findings suggest that being part of a social network, finding a sense of community and belonging in a positive and supportive environment will in turn lead to increased/sustained attendance. This is supported by Anderson and Whitfield (2013) who argued that social relationships are the foundation on which stroke-survivors rebuild their skills to engage with the world. Other studies have also confirmed that social support in group sessions is important in sustaining commitment by participants (Desrosiers et al 2008).

\section{Recommendations}

Based on the findings, several recommendations can be made for the development of a group exercise class tailored to the needs of this population:

- Include music to create a more relaxed environment and to engender a feeling of unity; 
- Ensure time is allocated for introductions and socialising at the beginning of class to allow mutual support and networking;

- Develop a simple programme based on purposeful exercises that can be explained during the class, to make an explicit link to a return to 'real' activities.

- Organise the class to allow activities to mimic activities of daily living performed at home e.g. seated circular formation around plinths to allow for standing activities that reflect home activities such as cooking).

\section{Limitations}

This study gathered perceptions of people with moderate to severe stroke, a population which has been excluded from many other studies investigating group-based programmes. However, the findings need to be considered in the light of some limitations. No Māori or Pacific participants were recruited, which reflects the ethnic make-up of the participating Hospital, as reported by the Auckland District Health Board (2014), and the limited timeframe for recruitment. There were a number of potential participants from other Asian groups (e.g. Chinese and Korean) who were not approached as they were unable to converse in English. The choice of convenience sampling and constraints on time and location meant that participant numbers were modest and we were limited in the level of diversity we could achieve. That said, the participant characteristics highlight a reasonable breadth of experience to aid transferability of findings.

\section{CONCLUSION}

This study provides an insight into the complexity and potential challenges for health professionals planning inpatient group-based programmes to include patients with more severe impairments. The findings from this research helped identify several potential key components for a group based programme, including the use of music accompaniment, allowing time and opportunity for socialising between group members, and an emphasis on empowering the participants through keeping them connected to the real world and by explaining the purpose of the desired exercises and facilitating their understanding of the rehabilitation process.

\section{KEY POINTS}

1. Physiotherapists need to acknowledge the impact of loss of self on the ability to engage in rehabilitation.

2. Group programmes need to allow patients the opportunity to forge social connections.

3. Programmes need to be meaningful and incorporate activities patients see as connected to the real world.

4. The therapeutic relationship may be a critical factor in maintaining engagement in a group programme.

\section{PERMISSIONS}

No permissions required for reproduction of material

\section{DISCLOSURES}

No funding was obtained for this research
The authors know of no conflicts of interest which may have interfered with or biased the research at any stage.

\section{ADDRESS FOR CORRESPONDENCE}

Nicola Saywell, School of Clinical Sciences, Health and Rehabilitation Research Institute, Auckland University of Technology, 90, Akoranga Drive, Northcote, Auckland. Telephone: 09 9219502. Email: nsaywell@aut.ac.nz

\section{REFERENCES}

Anderson S, Whitfield K (2013) Social identity and stroke: 'they don't make me feel like, there's something wrong with me'. Scandinavian Journal of Caring Sciences 27(4): 820-830. doi:10.1111/j.1471-6712.2012.01086.x.

Aprile I, Piazzini DB, Bertolini C, Caliandro P, Pazzaglia C, Tonali P, Padua $L$ (2006) Predictive variables on disability and quality of life in stroke outpatients undergoing rehabilitation. Neurological Sciences 27(1): 40-46.

Askim T, Bernhardt J, Løge AD, Indredavik B (2012) Stroke patients do not need to be inactive in the first two weeks after stroke: results from a stroke unit focused on early rehabilitation. International Journal of Stroke 7(1): 25-31. doi:10.1111/j.1747-4949.2011.00697.x.

Auckland District Health Board (2014) Auckland District Health Board Annual Report 2013/2014.

Bernhardt J, Dewey H, Thrift A, Donnan G (2004) Inactive and alone Physical activity within the first 14 days of acute stroke unit care. Stroke 35(4): 1005-1009.

Desrosiers J, Demers L, Robichaud L, Vincent C, Belleville S, Ska B (2008) Short-term changes in and predictors of participation of older adults after stroke following acute care or rehabilitation. Neurorehabilitation and Neural Repair 22(3): 288-297.

Ellis-Hill C, Payne S, Ward C (2008) Using stroke to explore the life thread model: an alternative approach to understanding rehabilitation following an acquired disability. Disability and Rehabilitation 30(2): 150-159.

Galvin R, Stokes E, Cusack T (2014) Family-Mediated Exercises (FAME): an exploration of participants' involvement in a novel form of exercise delivery after stroke. Topics in Stroke Rehabilitation 21(1): 63-74. doi:10.1310/ tsr2101-63.

Graham R, Kremer J, Wheeler G (2008) Physical exercise and psychological well-being among people with chronic illness and disability: a grounded approach. Journal of Health Psychology 13(4): 447-458. doi:10.1177/1359105308088515.

Hall AM, Ferreira PH, Maher CG, Latimer J, Ferreira ML (2010) The influence of the therapist-patient relationship on treatment outcome in physical rehabilitation: a systematic review. Physical Therapy 90(8): 1099-1110. doi:10.2522/ptj.20090245.

Hartman-Maeir A, Soroker N, Ring H, Avni N, Katz N (2007) Activities, participation and satisfaction one-year post stroke. Disability and Rehabilitation 29(7): 559-566.

Hsieh H-F, Shannon SE (2005) Three approaches to qualitative content analysis. Qualitative Health Research 15(9): 1277-1288.

Jun E-M, Roh YH, Kim MJ (2013) The effect of music-movement therapy on physical and psychological states of stroke patients. Journal of Clinical Nursing 22(1-2): 22-31. doi:10.1111/j.1365-2702.2012.04243.x.

Mangset M, Tor Erling D, Førde R, Wyller TB (2008) 'We're just sick people, nothing else': ... factors contributing to elderly stroke patients' satisfaction with rehabilitation. Clinical Rehabilitation 22(9): 825-835. doi:10.1177/0269215508091872

Ministry of Health (2014) Annual update of key results 2013/14: New Zealand Health Survey. Wellington.

Nicholson S, Sniehotta FF, van Wijck F, Greig CA, Johnston M, McMurdo MET, Dennis M, Mead GE (2013) A systematic review of perceived barriers and motivators to physical activity after stroke. International Journal of Stroke 8(5): 357-364. doi:10.1111/j.1747-4949.2012.00880.x. 
Poltawski L, Boddy K, Forster A, Goodwin VA, Pavey AC, Dean S (2015) Motivators for uptake and maintenance of exercise: perceptions of longterm stroke survivors and implications for design of exercise programmes. Disability and Rehabilitation 37(9): 795-801. doi:10.3109/09638288.201 4.946154.

Remer-Osborn J (1998) Psychological, behavioral, and environmental influences on post-stroke recovery. Topics in Stroke Rehabilitation 5(2): 45 53. doi:10.1310/F07L-LR38-N3EP-59B5.

Sandelowski M (2000) Whatever happened to qualitative description? Research in Nursing and Health 23(4): 334-340.

Schouten L, Murray C, Boshoff K, Sherman K, Patterson S (2011) Overcoming the long-term effects of stroke: qualitative perceptions of involvement in a group rehabilitation programme...includes commentary by Sherman $\mathrm{K}$ and Patterson S. International Journal of Therapy and Rehabilitation 18(4): $198-208111 p$

Slater H, Young J (2013) A review of brief cognitive assessment tests. Reviews in Clinical Gerontology 23(2): 164-176. doi:10.1017/ S0959259813000038.

Song HS, Kim JY, Park SD (2015) Effect of the class and individual applications of task-oriented circuit training on gait ability in patients with chronic stroke. Journal of Physical Therapy Science 27(1): 187-189. doi:10.1589/jpts.27.187

Sullivan-Bolyai S, Bova C, Harper D (2005) Developing and refining interventions in persons with health disparities: the use of qualitative description. Nursing Outlook 53(3): 127-133.

Townend E, Tinson D, Kwan J, Sharpe M (2010) 'Feeling sad and useless': an investigation into personal acceptance of disability and its association with depression following stroke. Clinical Rehabilitation 24(6): 555-564. doi:10.1177/0269215509358934.

\section{APPENDIX 1: Interview Question guidelines}

1. Can you tell me about your rehabilitation after stroke?

2. Can you tell me about a typical day in hospital?

3. What kind of exercises do you do in hospital?

4. Did you take part in any group exercises/activities while in hospital?

5. Do you prefer to do activities that you enjoy with others?

6. If you think about times when you could have been part of an activity in hospital, can you tell me what might have encouraged you to join?

7. Is there anything you dislike about group activities? If so, what do you dislike?

8. What else would you enjoy doing in a group?

9. What would you like to get back to doing? What do you feel you need to work on or improve to get back to doing these activities?

10. Would you like family or friends to be involved in your physical recovery?

11. What could we do to make it easier for you to be more active in the hospital?

12. If you could make a wish list of what you would like to do in hospital, what would it be? It does not have to be realistic. 